\title{
Agôn
}

Revue des arts de la scène

Critiques | Saison 2014-2015

\section{Vortex temporum (2013) d'Anne Teresa De Keersmaeker}

Cercles \& Impulsions

\section{Frédérique Villemur}

\section{OpenEdition}

Journals

Édition électronique

URL : http://journals.openedition.org/agon/3132

DOI : 10.4000/agon.3132

ISSN : 1961-8581

Éditeur

Association Agôn

Référence électronique

Frédérique Villemur, "Vortex temporum (2013) d'Anne Teresa De Keersmaeker », Agôn [En ligne],

Critiques, mis en ligne le 17 décembre 2014, consulté le 23 septembre 2020. URL : http://

journals.openedition.org/agon/3132 ; DOI : https://doi.org/10.4000/agon.3132

Ce document a été généré automatiquement le 23 septembre 2020.

Association Agôn et les auteurs des articles 


\title{
Vortex temporum (2013) d'Anne Teresa De Keersmaeker
}

\author{
Cercles \& Impulsions
}

Frédérique Villemur

\section{RÉFÉRENCE}

Vortex temporum (2013) d'Anne Teresa De Keersmaeker. Création en 2013

1 Une rosace, cinq cercles connectés à un cercle principal et élargis à la scène - signature d'Anne Teresa De Keersmaeker -, un piano isolé, cinq chaises face au public. Tracées à la craie, des ondes étirent sur le sol noir leur amplitude jusqu'aux marges du plateau, et tendent au regard la profondeur de spirales nouées. La complexité géométrique s'ouvre sur une perspective de lignes aux croisements multiples. Vortex temporum ${ }^{1}$, il faudrait oublier, ne pas savoir, ce qui du titre va s'imposer au regard, ce qui du temps et du vertige nous feront entendre le tourbillon de nos existences. Car ces lignes visibles sont à entendre autant qu'à regarder. Vortex temporum emprunte son titre à la partition musicale (1996) de Gérard Grisey, interprétée sur scène par le groupe Ictus dirigé par Georges-Elie Octors. La pièce se déroule en trois temps marqués par une séquence musicale inaugurale, puis un geste dansé en silence, enfin par la rencontre de la musique et de la danse. Mais contrairement à Cesena (2011) et En a(t)endant (2010) où les chanteurs se faisaient danseurs et les danseurs chanteurs, l'inversion des genres ne donne pas ici le change aux deux groupes. Le travail est tout autre. La rencontre passe à travers musique et geste en un rythme non apprivoisé, comme si musique et danse en oubli de leur virtuosité, sans rivaliser, exposaient leur rapport singulier au temps. 
Vortex temporum (2013) d'Anne Teresa De Keersmaeker

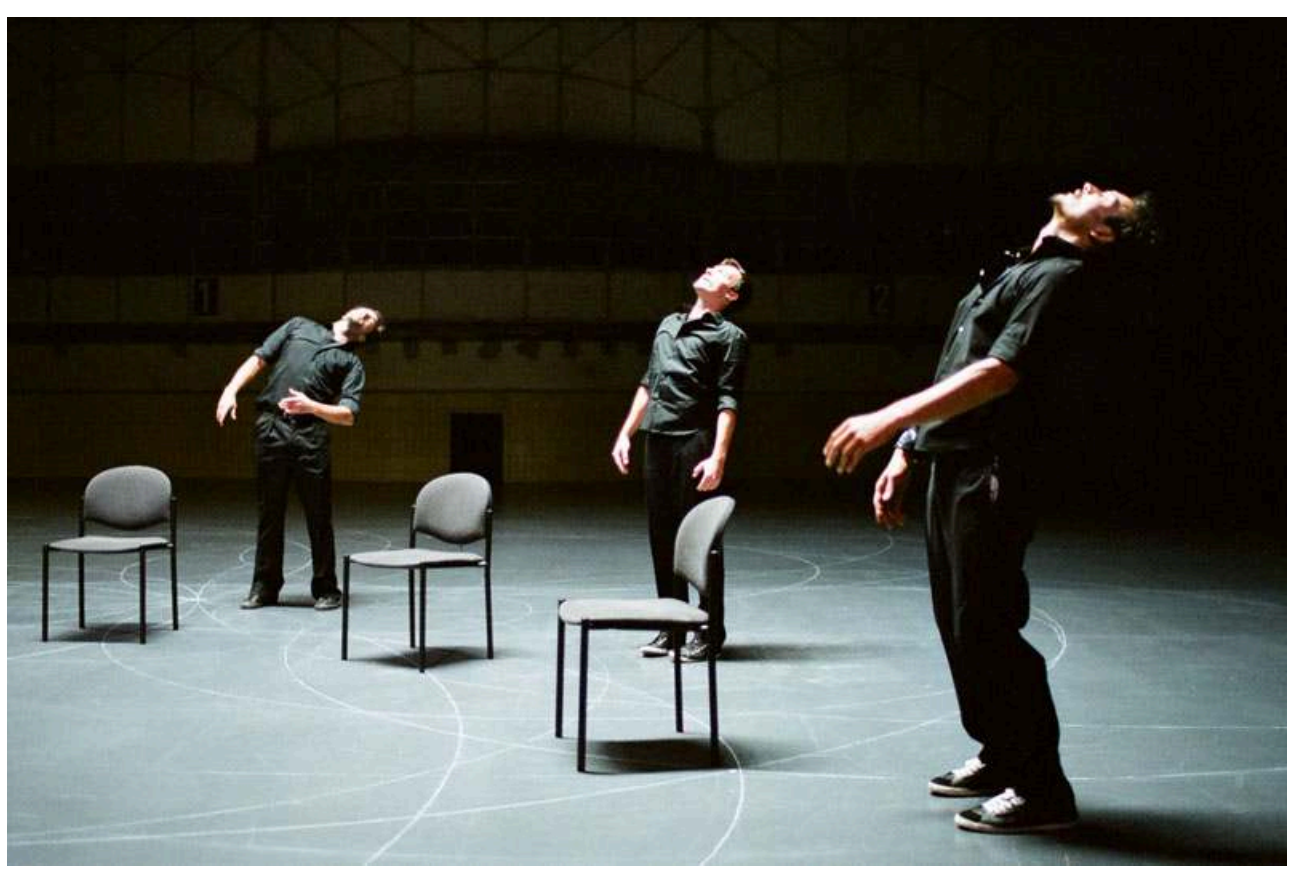

(c) Herman Sorgeloos

2 Le sextuor (piano, instruments à vents - flûte, clarinette, et à cordes - violon, alto, violoncelle) se saisit de l'introduction, les gestes sont vifs, les crins des archets volent, le fond sonore d'une boucle revient, et les attaques s'éprennent de détails qui tels des incises rappellent le nom de l'ensemble - Ictus, impulsion, attaque. La musique liminale de Gérard Grisey (1946-1998), caractéristique du courant spectral, travaille à la dilatation des sons, à la compression des spectres, à l'approfondissement d'un timbre : elle s'adonne toute entière à la transformation du matériau sonore. Gérard Grisey est à l'acoustique ce qu'Anne Teresa de Keersmaeker est au geste dansé: ou comment composer par l'écoute. Cependant les danseurs à leur tour investissent le plateau, silencieusement dansent. Ils dessinent depuis le vide d'un silence qu'ils laissent entendre à travers les lignes tendues à l'espace, les gestes de la danse. Il s'agit de tresser différentes qualités du temps, et lorsque les deux partitions musicale et dansée viennent à partager le plateau, on regrettera de voir le directeur de l'ensemble Ictus déplacer le piano avec son pianiste sur scène, les faire tourner parmi les danseurs. La musique avait-elle nécessité à mimer ainsi le geste de la danse ? Alors qu'elle se donne pleinement à entendre sous la danse - regarder la musique, écouter la danse : cercles entrelacés, spirales, volutes, en autant de lignes déployées. Ce vortex ne happe pas, il emporte. Ce sont moins des turbulences que des effets de résonances, moins des tumultes que des harmoniques et inharmoniques étirés et compressés. Dans la musique de Gérard Grisey, ce qui a fasciné Anne Teresa De Keersmaeker, c'est cette "temporalité liquéfiée, dit-elle, où la pulsation vacille et se dissout »². De fait, on remarque dans la partition musicale qu'une première onde sinusoïdale ouvre aux rythmes pointés dans lesquels se glisse le solo du piano, puis succèdent les mouvements ascendants des spectres sonores et les descentes chromatiques qui génèrent un mouvement hélicoïdal et continu : ainsi la métrique malmenée au cours du premier mouvement finit par être noyée dans le vertige d'une durée pure. 
Vortex temporum est une œuvre de la maturité, qui renoue avec les accents les plus anciens de Fase qui ont marqué l'entrée en danse d'Anne Teresa de Keersmaeker, avec ce qui en danse entre précisément en intimité plastique avec la musique par la voie du rythme. Elle a toujours travaillé le temps comme élément de variation du mouvement et comme durée globale, structure s'appuyant sur la logique interne d'une œuvre musicale. Pendant la création de la pièce, la chorégraphe dansait sur la Partita $N^{\circ} 2$ pour violon $^{3}$ de Bach. Une confrontation qui lui a permis de saisir un immense champ de possibilités pour la danse, ainsi que l'intensité du geste musical existant entre le corps du musicien et son instrument. Jamais autant les corps masculins chez Anne Teresa De Keersmaeker n'auront été si bien servis par ce travail sur la matière sonore : en pure attaque, et déliés tout à la fois.

Vortex temporum n'expose pas le temps d'un empressement contemporain comme on a pu le dire, ce serait rabattre la pièce sur une vérité documentaire. Il en va plutôt d'une interprétation sur le feuilletage du temps. Vortex temporum, c'est un temps qui permet de trouver dans ce qui le dilate et le contracte ce contrepoint qui l'accompagne et le contredit: le geste d'une conscience qui affleure depuis les profondeurs en un rythme dont notre corps se fait réceptacle. La fin de Vortex temporum tout particulièrement, qui s'achève sur un morceau sonore bien plus que dansé, laisse la main de la direction musicale de Georges-Elie Octors tournoyer en un halo de lumière. La main tenue en l'air à quelque intensité insoupçonnée, à une nouvelle figure ou suspension du temps. Ou la danse jusqu'au bout du geste musical. Rien ne sera trop montré, décidément, de ce qui lie la danse au rythme profond de l'écoute.

\section{NOTES}

1. Vortex temporum: production Rosas, co-production De Munt/ La Monnaie (Bruxelles), Ruhrtriennalle, Les Théâtres de la Ville de Luxembourg, Théâtre de la Ville (Paris), Sadler's Wells (Londres), Opéra de Lille, ImpulsTanz (Vienne), Holland Festival (Amsterdam), Concertgebouw Brugge (Bruges), 2013, crée et dansé par Boštjan Antončič, Carlos Garbin, Marie Goudot, Cynthia Loemij, Julien Monty, Michael Pomero, Igor Shyshko, avec les musiciens de l'ensemble Ictus, dirigé par Georges-Elie Octors, au piano, Jean-Luc Plouvier, flûte, Michael Schmid, clarinette, Dirk Descheemaeker, violon, Igor Semenoff, alto, Jeroen Robbrecht, violoncelle, Geert De Bièvre, durée : une heure. Tournée en cours : TNT, Toulouse, 5-6-7 décembre 2014 ; Vlaamse Opera, Gand (Belgique), 11-12 décembre 2014; Chassé Theater, Breda (Pays-Bas), 10 janvier 2015 ; La Scène nationale d'Orléans, 6 février 2015 ; Dansenshus, Stockholm (Suède), 20-21 février 2015 ; Théâtre de Cornouaille, Quimper, 22 mai 2015 ; Théâtre de Caen, 26 mai 2015 ; Künstlerhaus Hellerau, Dresde (Allemagne), 26-27 juin 2015.

2. Interview d'Anne Teresa De Keersmaeker par Bojana Cvejić , 19. 11. 2013, La Monnaie, Bruxelles. Mis en ligne à l'adresse suivante, URL : http://www.lamonnaie.be/fr/mymm/article/ 95/Interview-Anne-Teresa-De-Keersmaeker/

3. Voir également une critique de Frédérique Villemur, «Partita 2 (Sei solo) », Agôn [En ligne], Critiques, Saison 2013-2014, mis à jour le : 26/09/2014, URL : http://agon.ens-lyon.fr/index.php? id $=2711$ 